\title{
Squamous cell carcinoma arising from a long-standing epidermoid cyst of the back
}

Taeki Kim¹, Junhyung Kim', Jaehoon Choi ${ }^{1}$, Taehee Jo', Hye Won Lee ${ }^{2}$, Woonhyeok Jeong ${ }^{1}$

Departments of ${ }^{1}$ Plastic and Reconstructive Surgery and ${ }^{2}$ Pathology, Dongsan Medical Center, Keimyung University School of Medicine, Daegu, Korea

This research was supported by the BISA Research Grant from Keimyung University in 2019.
Epidermoid cysts are commonly encountered benign lesions in the field of plastic surgery, but their malignant transformation into squamous cell carcinoma (SCC) is extremely rare. A 68-year old woman with a cystic mass on her left lower back presented to our department. We excised the lesion under the suspicion of an epidermoid cyst or metastatic colon cancer based on the patient's medical history. The skin defect was covered with a split-thickness skin graft, and histopathological evaluation revealed the presence of SCC. Because of the low incidence of SCC arising from an epidermoid cyst, the mechanism of transformation of such cysts to SCC and the prognosis of this condition have not yet been well established. We therefore share the details of this rare case to contribute to the growing base of knowledge about SCC that arises from an epidermoid cyst.

Keywords Back / Epidermoid cyst / Squamous cell carcinoma / Skin neoplasms

\section{INTRODUCTION}

Epidermoid cysts are benign intradermal or subcutaneous tumors that are commonly encountered in clinical practice [1]. In the field of plastic surgery, cutaneous squamous cell carcinoma (SCC) is the second most common non-melanocytic skin cancer after basal cell carcinoma. Risk factors for SCC include sun exposure, exposure to ultraviolet radiation, immunosuppression, and human papillomavirus infection [2]. In addition to these risk factors, epidermoid cysts of the skin can progress to SCC in rare cases. A small number of cases have been described, and an incidence rate of $0.011 \%$ to $0.045 \%$ has been reported [3].

We present a case of SCC arising from a long-standing epidermoid cyst of the back in a 68 -year-old woman.

Received: Apr 28, 2020 Revised: Jun 15, 2020 Accepted: Jun 16, 2020

Correspondence: Woonhyeok Jeong Department of Plastic and

Reconstructive Surgery, Keimyung University School of Medicine, 1035 Dalgubeol-daero, Dalseo-gu, Daegu 42601, Korea

Tel: +82-53-258-7815, Fax: +82-53-258-4590, E-mail: psjeong0918@gmail.com

Copyright @ 2020 The Korean Society for Aesthetic Plastic Surgery.

This is an Open Access article distributed under the terms of the Creative Commons Attribution Non-Commercial License (https://creativecommons.org/licenses/by-nc/4.0/) which permits unrestricted non-commercial use, distribution, and reproduction in any medium, provided the original work is properly cited. www.e-aaps.org

\section{CASE REPORT}

A 68-year-old woman with a history of a right hemicolectomy for the treatment of adenocarcinoma of the colon 1 year prior presented to our department with a rapidly-growing fist-sized mass on her left lower back. The mass had been noticed by the patient 30 years earlier and was initially less than a few centimeters in diameter. Its size had increased to $10 \times 15 \mathrm{~cm}$ at the time of the hemicolectomy, and ultrasonography revealed a lobulated mass at the superficial subcutaneous level (Fig. 1). The mass was thought to be a large epidermoid cyst, but its focal heterogenous components made it suspicious for malignancy. The patient declined further evaluation for this anomaly and was discharged from the hospital.

Upon presentation, the patient reported tenderness and erythema, and a pus-like discharge was observed to emanate from a small fistula on the anterior surface of the mass (Fig. 2). Computed tomography revealed a growing hyperattenuating subcutaneous lesion in the left lower back, and subsequent positron emission tomography-computed tomography revealed hypermetabolism at the peripheral walls of the lesion (Fig. 3). Surgical excision was planned under the clinical impression of a large epidermoid cyst or metastatic cancer originating from the colon. Due to the possibility of malignancy, a wide excision with a $1-\mathrm{cm}$ margin was made, and SCC was confirmed via intraoperative frozen-section biopsy. The skin defect after excision measured $10 \times 15 \mathrm{~cm}$, and the exposed 


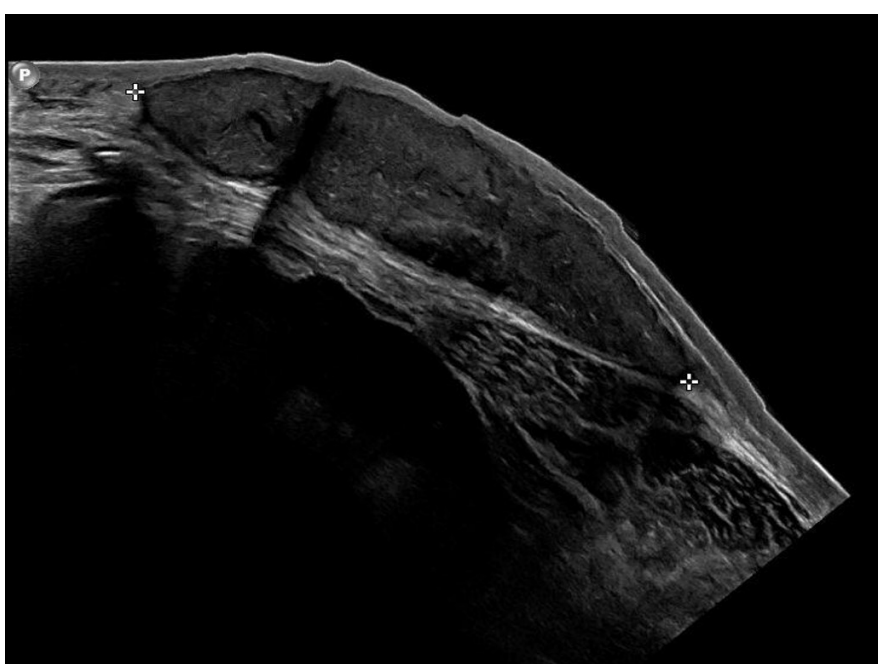

Fig. 1. A lobulated mass with a homogeneous component at the level of the superficial subcutaneous layer. A focal heterogenous anechoic area at the deep margin suggested possible malignancy.

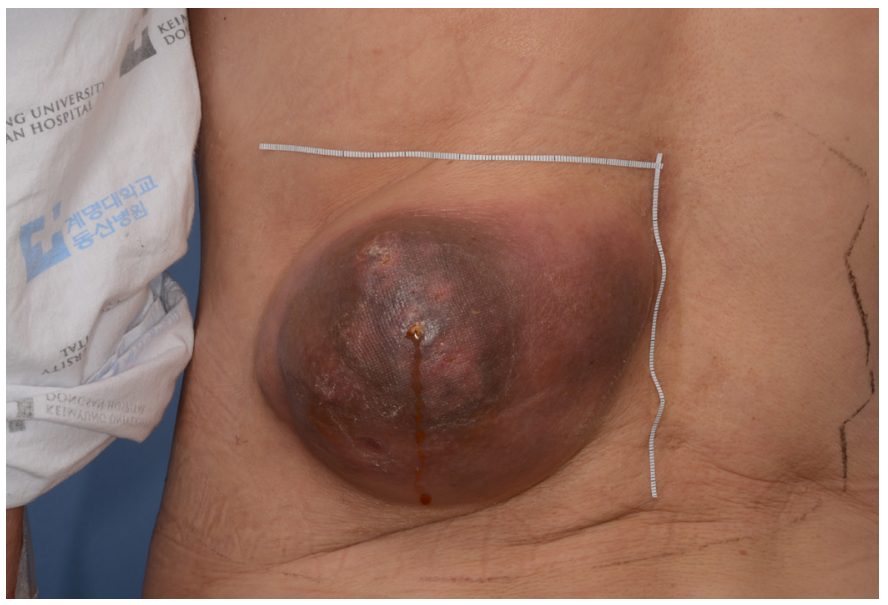

Fig. 2. A $15 \times 10-\mathrm{cm}$ massive mass with pus-like discharge on the left lower back.

subcutaneous tissues and muscle were covered with a split-thickness skin graft from the left posterior thigh (Fig. 4A). The cut section of the protruding dermal mass displayed a cystic cavity that was packed with friable chalky material (Fig. 5A). Microscopically, the cystic lesion had an epithelial lining and had invaded the dermis and subcutaneous tissue, but not the epidermis. The cystic cavity was filled with raw keratinous material comprising a partially matured squamous epithelium and lamellated keratin, typical of epidermoid cysts (Fig. 5B, right upper inlet). A regional foreignbody reaction was noted, but the majority of the region had transformed into SCC and was gradually connected to the epidermoid cyst region. The tumor was well-differentiated, but demonstrated characteristic malignant features, namely infiltrative individual nests, desmoplastic reaction, and cytologic atypia (Fig. 5B, right lower in-

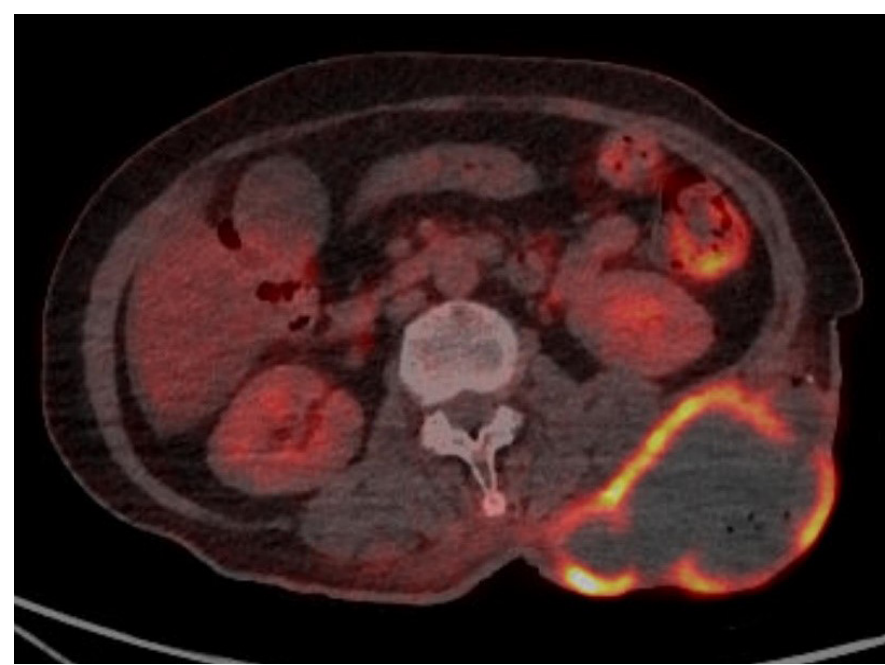

Fig. 3. Positron emission tomography image showing a large lowdensity mass with a hypermetabolic wall on the left lower back.
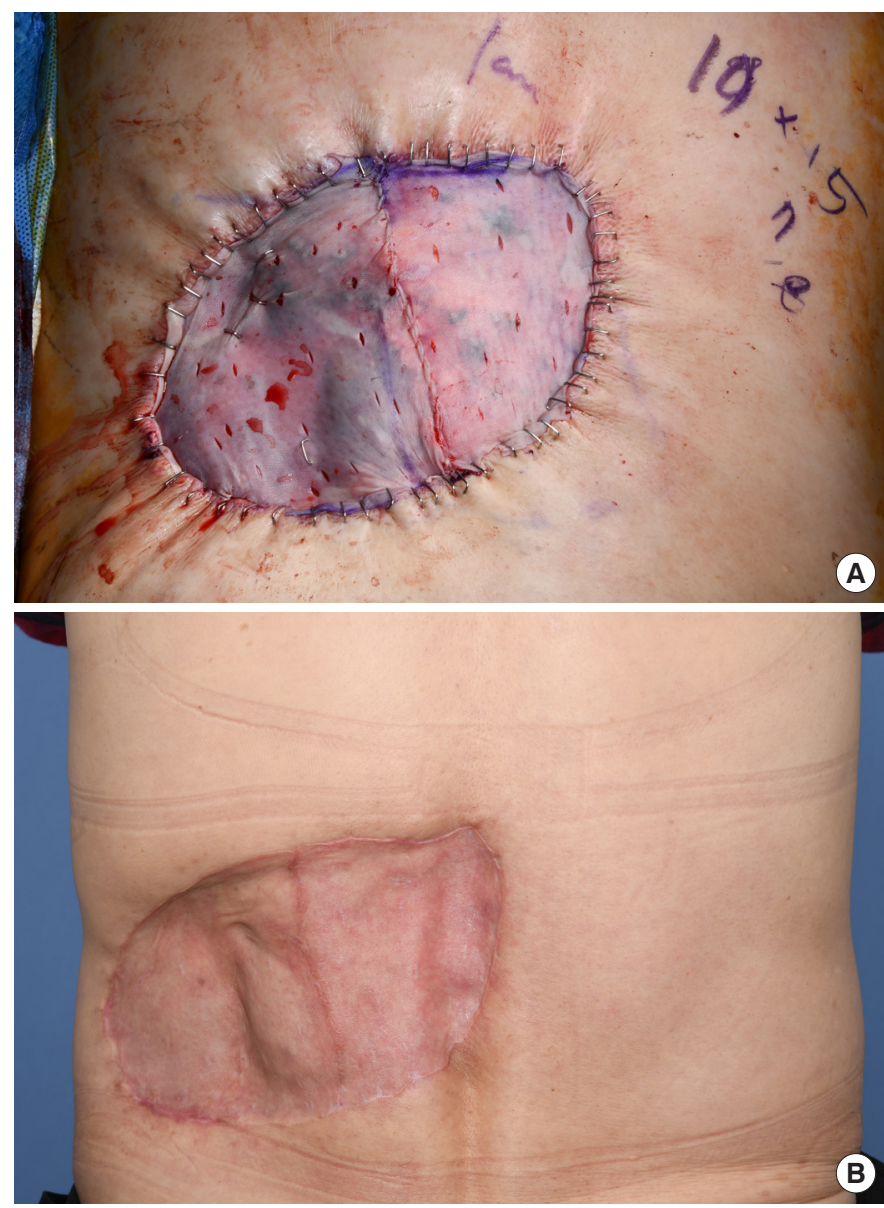

Fig. 4. Postoperative photographs. (A) After wide excision, the skin defect was covered with a purse-string suture and split-thickness skin graft $(15 \times 10 \mathrm{~cm}$, from the left posterior thigh). (B) By 5 months after surgery, the lesion had successfully healed without complications. 

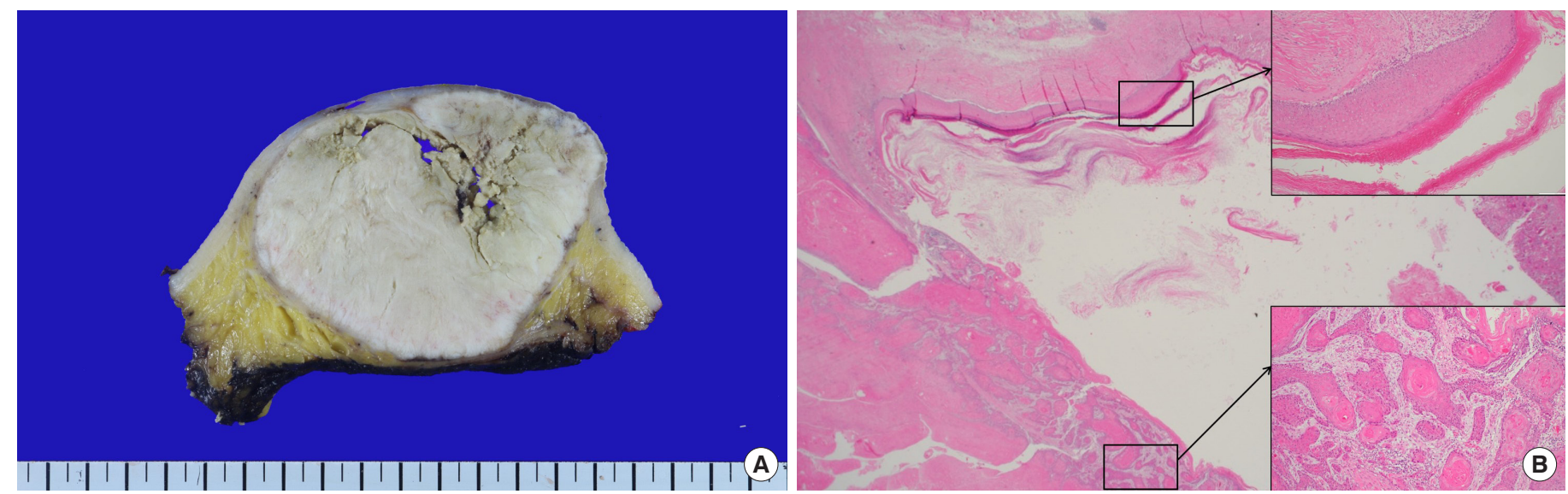

Fig. 5. Macroscopic and histological findings of the mass. (A) The cut surface revealed a circumscribed cyst filled with solid chalky white material. (B) Representative histological findings corresponding to the gross appearance of the tumor ( $\times 20)$. The cyst cavity was filled with homogenous keratin with calcification. A partial matured squamous epithelium with a granular layer was observed, similar to what is observed in conventional epidermoid cysts (right upper inlet, $\mathrm{H} \& \mathrm{E}, \times 100$ ). Definite squamous cell carcinoma was also observed (right lower inlet, H\&E, $\times 100$ ).

let). The diagnosis of SCC arising from an epidermoid cyst was therefore confirmed. The surgical margins were free of neoplastic involvement. The patient was discharged 13 days after surgery with no major complications. With no additional treatment, the lesion has shown no sign of recurrence as of 5 months after surgery (Fig. 4B).

\section{DISCUSSION}

Epidermoid cysts are common cutaneous cysts with epidermis-like epithelial walls. They are known by other names, such as epidermal cysts, infundibular cysts, epidermal inclusion cysts, and epidermoid inclusion cysts. Epidermoid cysts can appear on any part of the body, at any age, and may grow slowly [1]. Cutaneous epidermoid cysts are often benign, but a few cases of malignant transformation have been reported. SCC, basal cell carcinoma, Paget disease, Bowen disease, mycosis fungoides, Merkel cell carcinoma, and malignant melanoma are possible malignant tumors that can arise from epidermoid cysts [4]. Among these, SCC is the most common, and the reported transformation rate is $0.011 \%-0.045 \%[3,5]$.

Lopez-Rios et al. [5] were the first to present a literature review on the malignant transformation of epidermoid cysts. More recently, Frank et al. performed a cohort study of 41 cases from 1976 to 2018 , in which the researchers identified the head and neck as the most common site of SCC transformation (54.8\%). SCC arising from an epidermoid cyst has been reported to appear on all parts of the body, including the scrotum [6] and vulva [7], although only one case has been reported of its presentation on the back. In the study by Frank et al. [8], the mean diameter of the cysts was demonstrated to be $5.0 \mathrm{~cm}$, and the mean time from occurrence to diagnosis was 92.6 months, which is relatively short compared to the 30-year duration in the present case.

The mechanism of transformation from an epidermoid cyst to
SCC has yet to be established. The risk factors for SCC of the skin are radiation, immunosuppression, scars, and chronic inflammation [2], which are also considered risk factors for the malignant transformation of benign cysts. Chronic inflammation is a well-known and critical mechanism of malignant transformation to common tumors [9]; in the present case, we can presume that chronic inflammation was a crucial trigger, further exacerbated by repeated irritation due to the location of the lesion. Actinic damage and human paillomavirus (HPV) infection have also been proposed as etiological factors, but their involvement in the malignant transformation of epidermoid cysts to SCC has not been proven [10].

For the treatment of patients with cutaneous SCC, the anatomical location of the SCC is often considered an important risk factor. The scalp, eyelid, nose, and lips are the anatomical sites with highest risk of tumor extension. Additionally, the clinical size of the tumor is an important factor that impacts the risk of metastasis and recurrence. Furthermore, $90 \%$ of a cutaneous SCC can be eliminated with a low risk of metastasis using electrodesiccation and curettage, excision, or cryosurgery if the lesion is small and is located on the neck, trunk, arms, or legs. However, the reported cure rates of high-risk tumors after electrodesiccation and curettage are much lower than those after surgical excision, and cryotherapy is only an option for the treatment of small SCC lesions [11]. Moreover, in the present case of an SCC on the back, although the risk based on the anatomical site was low, its massive size made it a high-risk lesion, and we therefore chose surgical wide excision.

The primary treatment method for cutaneous SCC is wide excision with an adequate margin to facilitate tumor clearance. The appropriate surgical margins are $4 \mathrm{~mm}$ and $6 \mathrm{~mm}$ for tumors that superficially and deeply infiltrate subcutaneous tissue, respectively, and $9 \mathrm{~mm}$ for tumors with diameters of $20 \mathrm{~mm}$ or greater [12]. In our case, we resected the tumor with a generous $1-\mathrm{cm}$ margin due 
to its massive size and extended depth.

The course of clinical management and the prognosis after surgical excision have not been well established due to the rarity of this disease. Several warning symptoms such as pain, rapid growth, overlying skin changes, and persistent drainage can suggest neoplastic development [8]. In the present case, tenderness, erythema, and drainage were major symptoms, but these are also commonly observed in infected cysts. Histopathological analysis is therefore essential for the diagnosis of SCC originating from an epidermoid cyst. Although epidermoid cysts are commonly encountered in medicine, clinicians should always bear in mind that malignant changes can occur, even in the absence of warning symptoms. Therefore, routine histological examinations should be performed to identify malignant features such as cytologic atypia, perineural invasion, and an infiltrative pattern, especially in the cases of long-standing or symptomatic lesions. Furthermore, long-term follow-up data are necessary to thoroughly understand the mechanism of malignant transformation from an epidermoid cyst to SCC.

\section{NOTES}

\section{Conflict of interest}

No potential conflict of interest relevant to this article was reported.

\section{Ethical approval}

The study was approved by the Institutional Review Board of Dongsan Medical Center (IRB No. 2020-07070) and was performed in accordance with the principles of the Declaration of Helsinki.

\section{Patient consent}

The patient provided written informed consent for the publication and the use of her images.

\section{ORCID}

Taeki Kim

Junhyung Kim

Jaehoon Choi

https://orcid.org/0000-0002-8760-3546

https://orcid.org/0000-0001-9077-2853

https://orcid.org/0000-0001-6180-1619
Taehee Jo Hye Won Lee

Woonhyeok Jeong

https://orcid.org/0000-0001-8671-6429

https://orcid.org/0000-0001-8540-524X

https://orcid.org/0000-0002-0221-3347

\section{REFERENCES}

1. Hoang VT, Trinh CT, Nguyen CH, et al. Overview of epidermoid cyst. Eur J Radiol Open 2019;6:291-301.

2. Que SKT, Zwald FO, Schmults CD. Cutaneous squamous cell carcinoma: Incidence, risk factors, diagnosis, and staging. J Am Acad Dermatol 2018;78:237-47.

3. Anton-Badiola I, San Miguel-Fraile P, Peteiro-Cancelo A, et al. Squamous cell carcinoma arising on an epidermal inclusion cyst: a case presentation and review of the literature. Actas Dermosifiliogr 2010;101: 349-53.

4. Anastasios KV, Alexandra G, Anthony K, et al. Malignant transformation in a typical epidermal cutaneous cyst. J Med Cases 2012;3:254-6.

5. Lopez-Rios F, Rodriguez-Peralto JL, Castano E, et al. Squamous cell carcinoma arising in a cutaneous epidermal cyst: case report and literature review. Am J Dermatopathol 1999;21:174-7.

6. Yeh LP, Liao KS. Squamous cell carcinoma arising from an epidermal cyst of the scrotum. Ci Ji Yi Xue Za Zhi 2013;25:117-8.

7. Sze S, Richmond I, Bickers A, et al. Squamous cell carcinoma arising from a vulval epidermal cyst. J Obstet Gynaecol Res 2016;42:1623-6.

8. Frank E, Macias D, Hondorp B, et al. Incidental squamous cell carcinoma in an epidermal inclusion cyst: a case report and review of the literature. Case Rep Dermatol 2018;10:61-8.

9. Coussens LM, Werb Z. Inflammation and cancer. Nature 2002;420: 860-7.

10. Veenstra JJ, Choudhry S, Krajenta RJ, et al. Squamous cell carcinoma originating from cutaneous cysts: the Henry Ford experience and review of the literature. J Dermatolog Treat 2016;27:95-8.

11. Alam M, Ratner D. Cutaneous squamous-cell carcinoma. N Engl J Med 2001;344:975-83.

12. Brodland DG, Zitelli JA. Surgical margins for excision of primary cutaneous squamous cell carcinoma. J Am Acad Dermatol 1992;27(2 Pt 1):241-8. 